\title{
Free Hardware based System for Air Quality and CO2 Monitoring
}

\author{
Cristhoper Alvarez-Mendoza ${ }^{1}$, Jhon Vilchez-Lucana ${ }^{2}$, Fernando Sierra-Liñan ${ }^{3}$, Michael Cabanillas-Carbonell ${ }^{4}$ \\ Facultad de Ingeniería y Arquitectura, Universidad Autónoma del Perú, Lima, Perú ${ }^{1,2}$ \\ Facultad de Ingeniería, Universidad Privada del Norte, Lima, Perú ${ }^{3}$ \\ Vicerrectorado de Investigación, Universidad Norbert Wiener, Lima, Perú ${ }^{4}$
}

\begin{abstract}
Due to the increase in air pollution, especially in Latin American countries of low and middle income, great environmental and health risks have been generated, highlighting that there is more pollution in closed environments. Given this problem, it has been proposed to develop a system based on free hardware for monitoring air quality and $\mathrm{CO} 2$, in order to reduce the levels of air pollution in a closed environment, improving the quality of life of people and contributing to the awareness of the damage caused to the environment by the hand of man himself. The system is based on V-Model, complemented with a ventilation prototype implemented with sensors and an application for its respective monitoring. The sample collected in the present investigation was non-probabilistic, derived from the reports of air indicators during $\mathbf{1 5}$ days with specific schedules of $9 \mathrm{am}, 1 \mathrm{pm}$ and $6 \mathrm{pm}$. The results obtained indicated that the air quality decreased to $670 \mathrm{ppm}$, as well as the collection time decreased to 5 seconds and finally the presence of $\mathrm{CO} 2$ was reduced to $650 \mathrm{ppm}$ after the implementation of the system, achieving to be within the standards recommended by the World Health Organization.
\end{abstract}

Keywords-Air quality; air pollution; co2; control system; free hardware; v-model

\section{INTRODUCTION}

Air pollution is a negative effect that has been aggravated over the years, the development of the population has generated new demands in homes, industries and public centers, bringing as a consequence the continuous pollution of the environment and multiple diseases [1]. One of the main causes of the increase in carbon dioxide (CO2) is the burning of fuel [2].

Recent studies affirm that there is a higher concentration of pollutant gases in closed environments than outdoors [3]. The World Health Organization (WHO) [4], states that, due to indoor air pollution, public health, especially that of children and the elderly, is being affected. Currently the rate of premature death of children amounts to 7 million, this is due to the concentration of gases such as $\mathrm{CO} 2$, which generates suffering from asthma, reduced growth and respiratory problems.

Air quality is expressed by the high concentration of several gases, the main one being $\mathrm{CO} 2$, likewise the WHO mentioned that the allowed value to improve air quality in indoor environments is between 800 and $1000 \mathrm{ppm}$ (unit to measure the volume of particles), due to the pollutants found in the air [4]-[6]. According to the report presented by Air Quality Life Index (AQLI) in the last year [7], it was identified that half of the Latin American population receives dangerous levels of pollution, with Peru being one of the countries with the most critical points, having the inhabitants of its capital (Lima) with a life expectancy of 4.7 years reduced due to air pollution (Fig. 1).

Current technological and scientific progress has driven the development of systems that improve people's quality of life, providing welfare to the community by providing relevant and pertinent information for decision making. In the technological context of the Internet of Things (IoT), these systems involve the measurement and monitoring of various environmental variables [8], supported together with the use of free hardware, which has had a growing use being used in any type of project without the need to purchase a license [9]. The data obtained from the electronic devices will later prove to be important for raising public awareness of the level of air pollution present in our environment, which damages our health.

The proposed control system aims to provide an alternative system based on free hardware for air quality management in a closed facility, in order to reduce the pollutant gases in that place. This will be achieved by making use of different components such as sensors and communication devices, interacting with each other and obtaining the data of the gases under study, to later analyze if they exceed the established standards and act automatically, finally turn on the necessary components and ventilate the environment.

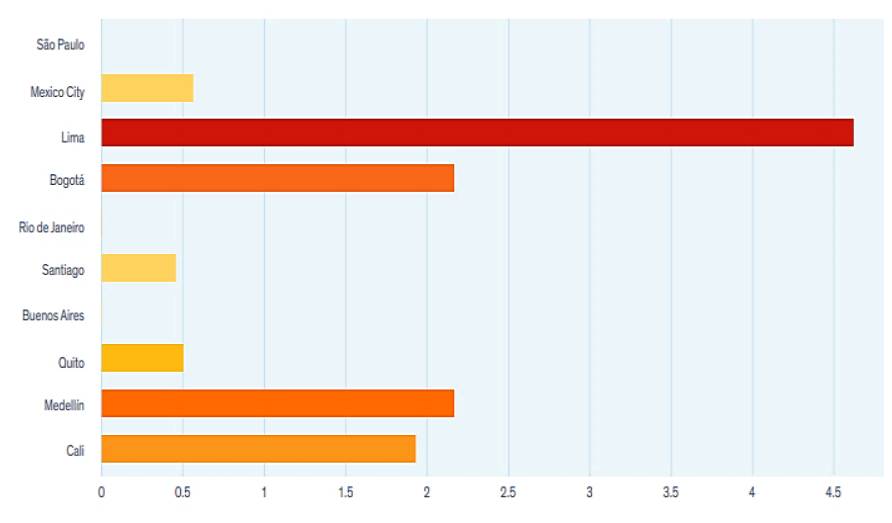

Fig. 1. Reduction of Life Expectancy Years due to PM2.5 Concentrations (Organic Chemicals Suspended in the Air) in 10 Largest Cities in Latin America [7]. 
This article has been organized in six different sections to achieve a better understanding: Section II contains the bibliographic review carried out after the study of previous research related to the subject under study. Section III details the development of the methodology applied, as well as the development of the proposed system. Section IV shows the results obtained after the pre- and post-implementation of the system, as well as the summary reports of each indicator evaluated. Section V contains the discussions, as well as the subsequent analysis of the results. Finally, section VI details the conclusions obtained from the development and implementation of the system.

\section{REVIEW OF THE LITERATURE}

The development of a control system is aimed at the systematic or manual management of the technological components in a simple and effective way, which is why we propose the development of a control system that helps reduce $\mathrm{CO} 2$ emissions by monitoring air quality to improve the purification and maintenance of this at normal levels.

According to what was investigated, it was possible to gather proposals of solutions from different authors regarding the problems that arise in the control of air quality, thus contributing to the research carried out. To achieve this, it was necessary to identify the degree of contamination and the quality of the air provided in the environment of a population and the factors that influence it [10], resulting to have a direct relationship with respiratory problems, cardiovascular, lung cancer, among other related diseases, this is due to the fact that the WHO guidelines [11], [12] were not taken into account. Regarding indoor air quality, the risk is doubled due to constant exposure to high levels of smoke [12], [13], therefore WHO has considered the training of countries with higher pollution rates through the use of monitoring technologies, workshops, etc.

Likewise, the contribution of the research [14] was considered, it proposed a system to measure the air quality in five routes by means of monitoring sensors in vehicles, collecting data from the cluster without the need for a fixed network structure, making recommendations in the course of travel through an application and social networks, thus contributing to the use of health-conscious transportation.

On the other hand, an IOT-based system was proposed through wireless networks based on connections through web services protocols, data transmission and data encryption because it is intended for smart buildings [15], proposing a free hardware design thinking about the functionality and scalability of it, aiming to predict and control the $\mathrm{CO} 2$ gas which is produced by people. The tools implemented proved to be efficient in recording data for future predictions and environmental controls, in addition to having great energy savings.

In Ref. [16], a 2-year study was conducted at different air quality stations based on the evaluation of particulate matter (PM10) in 3 districts of the province of La Oroya in Peru, one of the mining sites with the highest exposure to air pollution. The sources of emissions, the verification with respect to emission and immission standards and the type of pollutant that exists at the site were verified; by having this information, it was possible to determine the level of risk and environmental impact that existed at the site, evidencing an improvement over the years.

This section explores previous studies on the different tools that have been developed to control and monitor air quality in real time, which was necessary for the development of this research, identifying the sensors already used before. This is due to the need of people to know the state of air quality in their environment since it generally has a direct impact on health [17]. Table I summarizes recent developments in these tools and techniques.

TABLE I. Previous STUdies In ReAl Time Air Quality Monitoring AND CONTROL

\begin{tabular}{|c|c|c|c|}
\hline Tool & Ref. & Technology & Conclusions \\
\hline AirCloud & [18] & $\begin{array}{l}\text { Two air quality } \\
\text { monitoring devices } \\
\text { were developed using } \\
\text { PPD42NJ sensors to } \\
\text { acquire data. }\end{array}$ & $\begin{array}{l}\text { A low-cost, personal air } \\
\text { quality monitoring } \\
\text { system capable of } \\
\text { achieving good PM2.5 } \\
\text { prediction accuracies } \\
\text { was obtained. }\end{array}$ \\
\hline $\begin{array}{l}\text { WSN } \\
\text { based AQM }\end{array}$ & [19] & $\begin{array}{l}\text { Zigbee WSN was } \\
\text { used, employing gas } \\
\text { sensors for (CO2, } \\
\text { NO2, ozone). }\end{array}$ & $\begin{array}{l}\text { Clustering energy- } \\
\text { efficient air sensor } \\
\text { protocol was introduced } \\
\text { to monitor air quality. }\end{array}$ \\
\hline AirSense & [20] & $\begin{array}{l}\text { Use was made of the } \\
\text { MQ-135 sensor } \\
\text { connected to the } \\
\text { Arduino Pro Mini, the } \\
\text { sensor data was } \\
\text { collected using } \\
\text { ThingSpeak. }\end{array}$ & $\begin{array}{l}\text { A dual-purpose, low- } \\
\text { power, low-weight } \\
\text { system was obtained } \\
\text { that was able to detect } \\
\text { and collect data. }\end{array}$ \\
\hline $\begin{array}{l}\text { IoT- } \\
\text { enabled AQM }\end{array}$ & [21], & $\begin{array}{l}\text { Use was made of } \\
\text { several sensors } \\
\text { deployed on Marvel } \\
\text { Board and AWS } \\
\text { cloud. }\end{array}$ & $\begin{array}{l}\text { It is less expensive and } \\
\text { has high fidelity. Due } \\
\text { to the cloud platform } \\
\text { special limitations are } \\
\text { overcome. }\end{array}$ \\
\hline $\begin{array}{l}\text { IoT-Raspberry } \\
\text { PI }\end{array}$ & {$[22]$} & $\begin{array}{l}\text { It required integrating } \\
\text { different types of } \\
\text { sensors with the } \\
\text { Raspberry } \mathrm{Pi} \text {, } \\
\text { controlling and } \\
\text { managing them all } \\
\text { using Python. }\end{array}$ & $\begin{array}{l}\text { Analyzes some } \\
\text { hazardous gases such as } \\
\text { carbon monoxide (CO), } \\
\text { nitrogen dioxide (NO2) } \\
\text { and other gases. }\end{array}$ \\
\hline $\begin{array}{l}\text { (IoT) based air } \\
\text { quality } \\
\text { monitoring } \\
\text { system }\end{array}$ & [23] & $\begin{array}{l}\text { It was able to address } \\
\text { Malaysia's concern } \\
\text { about the delay } \\
\text { announcement and } \\
\text { measurement of } \\
\text { PM2.5 haze. }\end{array}$ & $\begin{array}{l}\text { The system monitors } \\
\text { common air pollutants } \\
\text { such as particulate } \\
\text { matter (PM) of PM2.5, } \\
\text { PM10 and carbon } \\
\text { monoxide (CO) gas. }\end{array}$ \\
\hline $\begin{array}{l}\text { Genetic } \\
\text { algorithm and } \\
\text { neural } \\
\text { network }\end{array}$ & [24] & $\begin{array}{l}\text { An optimized air } \\
\text { quality estimation } \\
\text { model was developed } \\
\text { based on a genetic } \\
\text { algorithm and an } \\
\text { artificial neural } \\
\text { network. }\end{array}$ & $\begin{array}{l}\text { The optimized network } \\
\text { model is used to } \\
\text { estimate the carbon } \\
\text { monoxide } \\
\text { concentration in a } \\
\text { polluted environment. }\end{array}$ \\
\hline
\end{tabular}

\section{Methodology}

The methodology used for the development of the project was the V-Model, which is used for software development by establishing the course of the project through phases, having as one of its main benefits to define the processes of quality management that can interact with the phases with each other 
[25]. This model allows integration tests to be performed as the phases are completed, allowing to verify the progress of each of the add-ons, helping to avoid errors.

\section{A. Population and Sample}

The study population consisted of the number of reports of air quality indicators in the "24 de Junio" shopping center located in the city of Lima. The type of sample collected in this research was non-probabilistic, derived from the reports of air quality indicators during 15 days with specific hours of 9am, $1 \mathrm{pm}$ and $6 \mathrm{pm}$.

\section{B. Development of $V$-Model}

1) Phase I-Specifications: In this phase all the functional and non-functional requirements for the construction of the hardware and also the application were conceptualized.

2) Phase II: Global Design: In this phase, the design of the overall solution was carried out. Fig. 2 shows the connection between the ESP8266 board and the MQ-135 (air quality) and MG-811 (CO2 sensor) sensors.

The complete system architecture for the subsequent air control operation and the application model is shown in Fig. 3.

The user visualizes the level of contamination present at the site, the board collects data from the sensors and sends it to both the application and the ventilation system to be turned on or off.

3) Phase III - Detailed Design: Fig. 4 shows the communication model of the devices used, where the Esp8266 Wi-Fi chip collects the information from the sensors and how it is sent to the application, and also shows the automation of the ventilation set. The user can visualize the air quality level of the shopping center from any place where he/she has an internet connection.

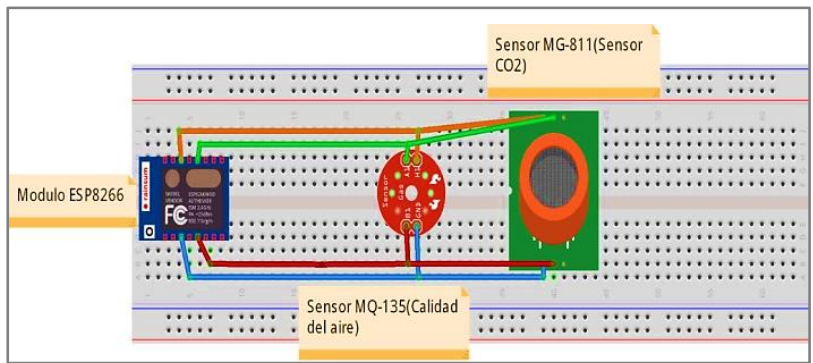

Fig. 2. Prototype Design

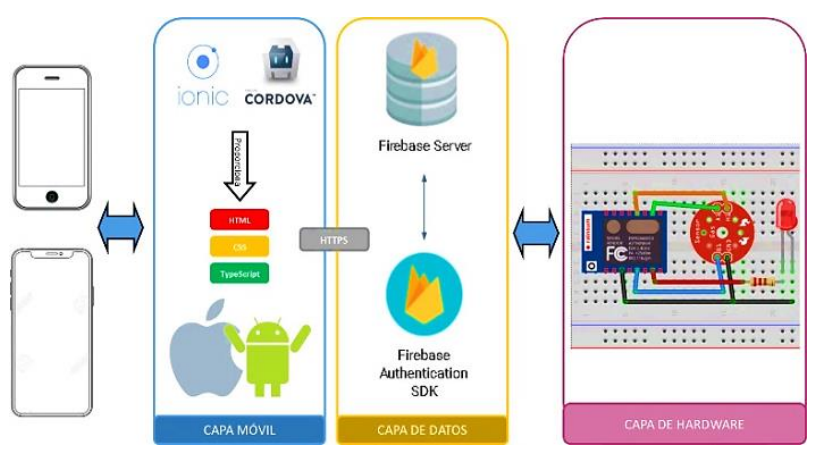

Fig. 3. General Architecture of the Proposed System.

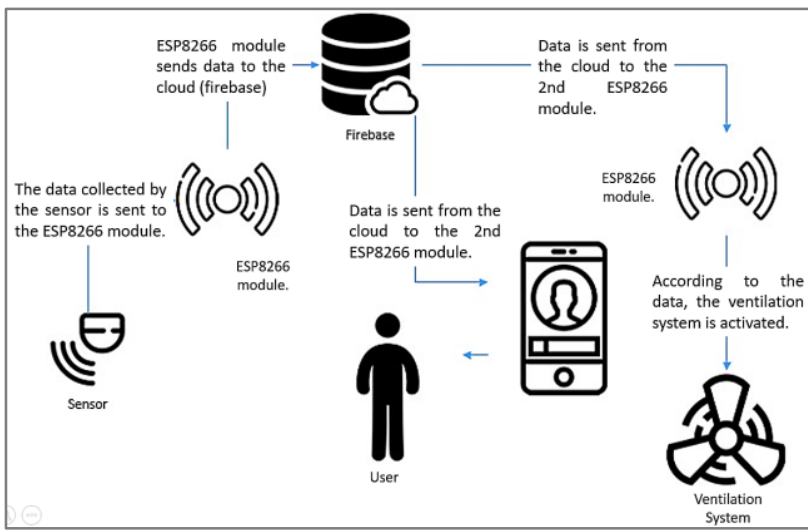

Fig. 4. Communication Model between Devices.

4) Phase IV - Implementation and Integration: In this phase, all the requirements of Phase I regarding the control system (Fig. 5) and the application (Fig. 7) were incorporated and implemented.

The system was programmed Fig. 6(a) and then the data captured by the measurement sensors were analyzed to verify the state of the air. After the sensor collected the data, they were analyzed internally in the ESP8266, first verifying if the air was within the allowed margins as shown in Fig. 6 (b).

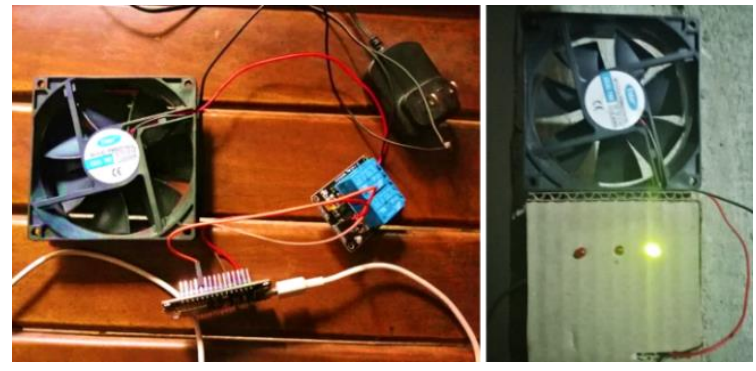

Fig. 5. Control System Integration.

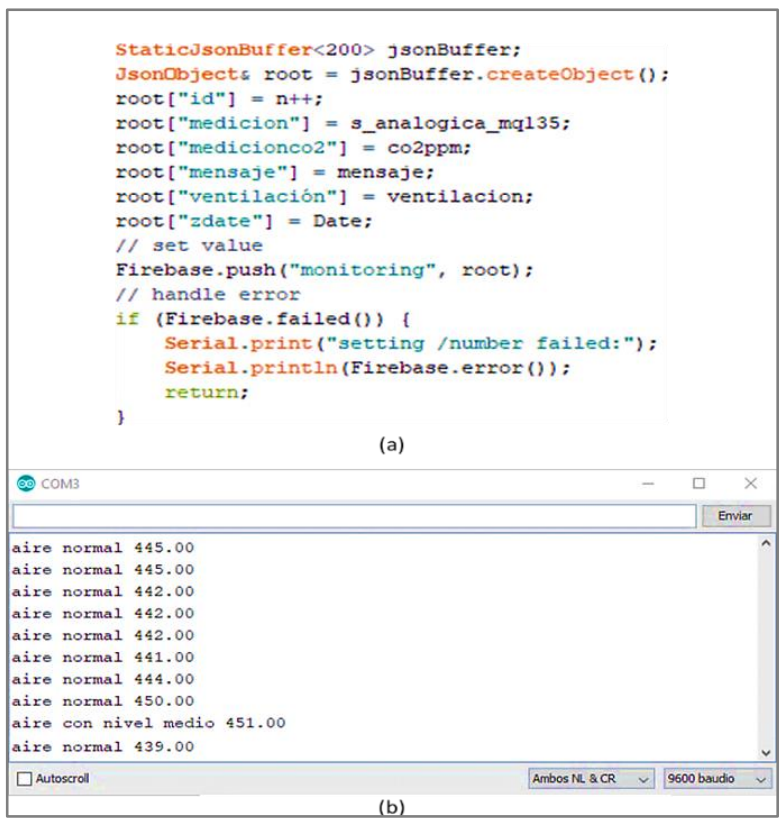

Fig. 6. Tests to the Developed Prototype. 


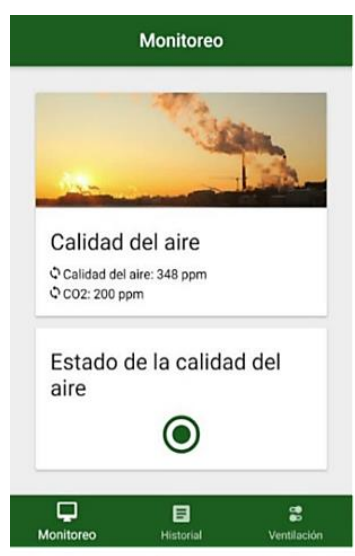

(a)

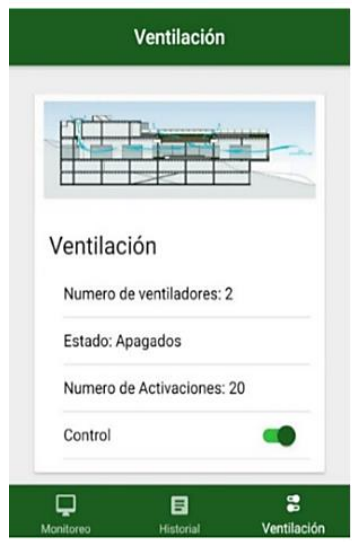

(c)

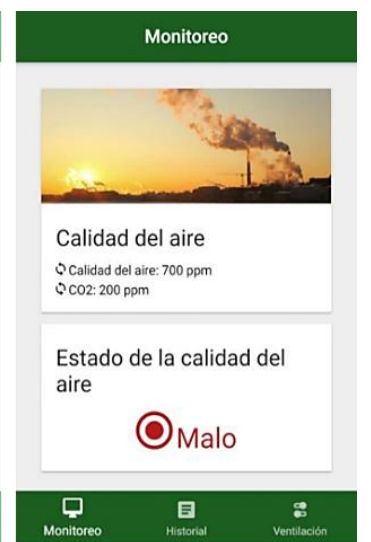

(b)

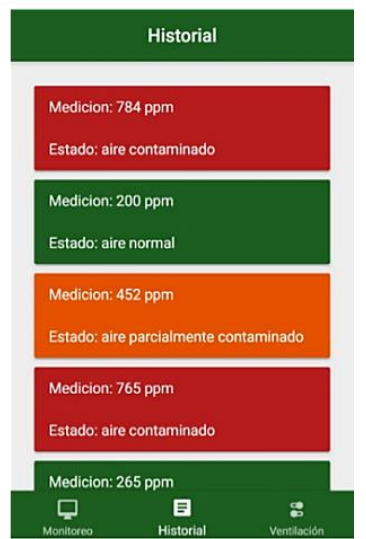

(d)
Fig. 7. Interfaces and Application Testing.

Fig. 7 shows the developed application which fulfills the function of receiving the data in real time, so that it can be seen by the users. In Fig. 7(a) and Fig. 7(b) the application shows the states (red, yellow and green) depending on the quality of the captured air, as specified in Table II. Fig. 7(c) shows that the application has a switch which allows the control of the ventilation system. In addition, in Fig. 7(d) the application shows the air history of the last 10 measurements of each hour specified in addition each shows a color depending on the air quality measurement in those ranges.

5) Phase V - System Operational Test: In the last phase, everything that was done was analyzed, drawing conclusions on the actions that went well and those that need to be improved in the project.

A pre-experimental design with pre- and post-test was applied to this research (1).

$\mathrm{Ge} \mathrm{O}_{1} \mathrm{X}^{\mathrm{O}_{2}}$

TABLE II. StATES OF THE PROTOTYPE DEPENDING ON AIR QUALITY

\begin{tabular}{|l|l|}
\hline States & Action \\
\hline Good & The status turns green indicating that the air is clean. \\
\hline Medium & $\begin{array}{l}\text { The state turns a yellow color indicating that the air is not as } \\
\text { pure. }\end{array}$ \\
\hline Poor & The status turns red which indicates that the air is very polluted. \\
\hline
\end{tabular}

Where:

- Ge: Experimental group: the study is given to the air during 3 specific times in the day.

- O1: Pre-Test data for the dependent variable indicator before the implementation of the control system. PreTest measurement of the experimental group.

- O2: Post-Test data for the indicator of the dependent variable. Post-Test measurement of the experimental group.

- X: Control System $=$ The object to be tested.

\section{RESULTS}

Table III shows the data obtained in the Pre and Post Test of the KPI1, KPI2 and KPI3 of the present research.

TABLE III. RESUlts ObTAINEd From the Pre-TEST AND Post-TeST

\begin{tabular}{|c|c|c|c|c|c|c|c|}
\hline \multirow{2}{*}{$\begin{array}{l}\# \\
\text { Days }\end{array}$} & \multirow{2}{*}{$\begin{array}{l}\text { Specific } \\
\text { hours }\end{array}$} & \multicolumn{2}{|c|}{ KPI_1 } & \multicolumn{2}{|c|}{ KPI_2 } & \multicolumn{2}{|c|}{ KPI_3 } \\
\hline & & Pre & Post & Pre & Post & Pre & Post \\
\hline \multirow{3}{*}{1} & 09:00 a. m. & 950 & 700 & 790 & 660 & 300 & 6 \\
\hline & 01:00 p. m. & 1520 & 1270 & 1365 & 1120 & 350 & 5 \\
\hline & 06:00 p. m. & 1030 & 780 & 878 & 748 & 240 & 9 \\
\hline \multirow{3}{*}{2} & 09:00 a. m. & 870 & 620 & 716 & 586 & 290 & 7 \\
\hline & 01:00 p. m. & 1420 & 1170 & 1267 & 1100 & 300 & 7 \\
\hline & 06:00 p. m. & 930 & 680 & 771 & 641 & 240 & 5 \\
\hline \multirow{3}{*}{3} & 09:00 a. m. & 920 & 670 & 760 & 630 & 300 & 7 \\
\hline & 01:00 p. m. & 1260 & 1010 & 1095 & 920 & 270 & 8 \\
\hline & 06:00 p. m. & 870 & 620 & 712 & 582 & 250 & 5 \\
\hline \multirow{3}{*}{4} & 09:00 a. m. & 670 & 420 & 518 & 388 & 220 & 8 \\
\hline & 01:00 p. m. & 1326 & 1076 & 1172 & 1042 & 200 & 7 \\
\hline & 06:00 p. m. & 846 & 596 & 687 & 557 & 260 & 6 \\
\hline \multirow{3}{*}{5} & 09:00 a. m. & 720 & 470 & 556 & 426 & 260 & 6 \\
\hline & 01:00 p. m. & 1463 & 1213 & 1293 & 1163 & 240 & 7 \\
\hline & 06:00 p. m. & 823 & 573 & 656 & 526 & 240 & 9 \\
\hline \multirow{3}{*}{6} & 09:00 a. m. & 820 & 570 & 655 & 525 & 310 & 6 \\
\hline & 01:00 p. m. & 1260 & 1010 & 1093 & 963 & 305 & 6 \\
\hline & 06:00 p. m. & 680 & 430 & 525 & 395 & 230 & 6 \\
\hline \multirow{3}{*}{7} & 09:00 a. m. & 640 & 390 & 482 & 352 & 290 & 5 \\
\hline & 01:00 p. m. & 1050 & 920 & 885 & 800 & 270 & 6 \\
\hline & 06:00 p. m. & 820 & 570 & 665 & 535 & 233 & 9 \\
\hline \multirow{3}{*}{8} & 09:00 a. m. & 740 & 490 & 587 & 457 & 305 & 7 \\
\hline & 01:00 p. m. & 1160 & 910 & 990 & 900 & 240 & 5 \\
\hline & 06:00 p. m. & 901 & 651 & 737 & 607 & 120 & 6 \\
\hline \multirow{3}{*}{9} & 09:00 a. m. & 810 & 560 & 650 & 520 & 130 & 5 \\
\hline & 01:00 p. m. & 1362 & 1112 & 1201 & 1071 & 205 & 8 \\
\hline & 06:00 p. m. & 1025 & 775 & 867 & 737 & 100 & 5 \\
\hline \multirow{2}{*}{10} & 09:00 a. m. & 720 & 470 & 565 & 435 & 160 & 8 \\
\hline & 01:00 p. m. & 1060 & 810 & 904 & 774 & 200 & 6 \\
\hline
\end{tabular}




\begin{tabular}{|c|c|c|c|c|c|c|c|}
\hline \multirow{3}{*}{$\begin{array}{l}\# \\
\text { Days }\end{array}$} & \multirow{2}{*}{$\begin{array}{l}\text { Specific } \\
\text { hours }\end{array}$} & \multicolumn{2}{|c|}{ KPI_1 } & \multicolumn{2}{|c|}{ KPI_2 } & \multicolumn{2}{|c|}{ KPI_3 } \\
\hline & & Pre & Post & Pre & Post & Pre & Post \\
\hline & 06:00 p. m. & 852 & 602 & 682 & 552 & 320 & 5 \\
\hline \multirow{3}{*}{11} & 09:00 a. m. & 860 & 610 & 705 & 575 & 203 & 5 \\
\hline & 01:00 p. m. & 1630 & 1380 & 1470 & 1340 & 156 & 5 \\
\hline & 06:00 p. m. & 945 & 695 & 784 & 654 & 198 & 5 \\
\hline \multirow{3}{*}{12} & 09:00 a. m. & 630 & 380 & 471 & 341 & 248 & 6 \\
\hline & 01:00 p. m. & 960 & 710 & 790 & 660 & 310 & 6 \\
\hline & 06:00 p. m. & 730 & 480 & 571 & 441 & 204 & 8 \\
\hline \multirow{3}{*}{13} & 09:00 a. m. & 790 & 540 & 600 & 470 & 302 & 7 \\
\hline & 01:00 p. m. & 1230 & 1000 & 1060 & 930 & 209 & 8 \\
\hline & 06:00 p. m. & 1040 & 790 & 870 & 740 & 281 & 8 \\
\hline \multirow{3}{*}{14} & 09:00 a. m. & 650 & 400 & 476 & 346 & 295 & 8 \\
\hline & 01:00 p. m. & 1020 & 870 & 842 & 712 & 333 & 7 \\
\hline & 06:00 p. m. & 720 & 470 & 568 & 438 & 220 & 6 \\
\hline \multirow{3}{*}{15} & 09:00 a. m. & 890 & 640 & 735 & 605 & 250 & 6 \\
\hline & 01:00 p. m. & 1530 & 1280 & 1367 & 1237 & 240 & 7 \\
\hline & 06:00 p. m. & 903 & 653 & 742 & 612 & 270 & 8 \\
\hline
\end{tabular}

Table IV shows the average results obtained for each KPI of the research; these results were derived from the analysis of Table III.

The results in the three KPI's, both pre and post, performed 15 days later, show a decrease for each indicator (Table IV), which means that the control system was of great support to reduce air quality and $\mathrm{CO} 2$ pollution.

From Fig. 8, where each indicator is measured with different index tests which varies between 0 - 1200, it can be observed that the average of KPI I is the one that has been reduced the most with respect to the other KPI's, it can be said that there is a better air quality.

TABLE IV. RESEARCH INDICATORS

\begin{tabular}{|l|l|l|}
\hline Indicator & Pre-Test & Post-Test \\
\hline KPI I: Volume level of air quality pollution. & 978.80 & 734.13 \\
\hline KPI II: Volume level of CO2 pollution. & 817.22 & 684.73 \\
\hline KPI III: Time to obtain information from the air. & 246.60 & 6.55 \\
\hline
\end{tabular}

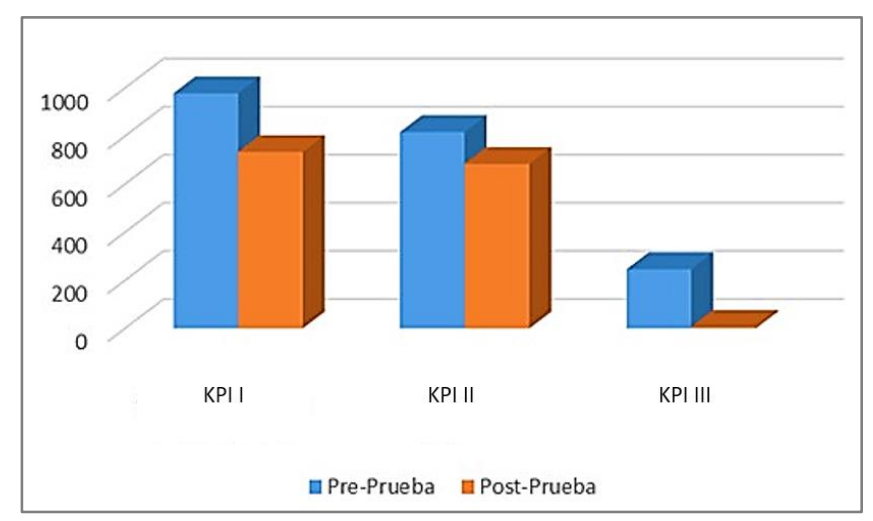

Fig. 8. Comparison of Pre- and Post-test KPI's.

\section{A. Results of the First Indicator (KPI - I)}

The summary report of the first post-implementation indicator of the system is shown in Fig. 9.

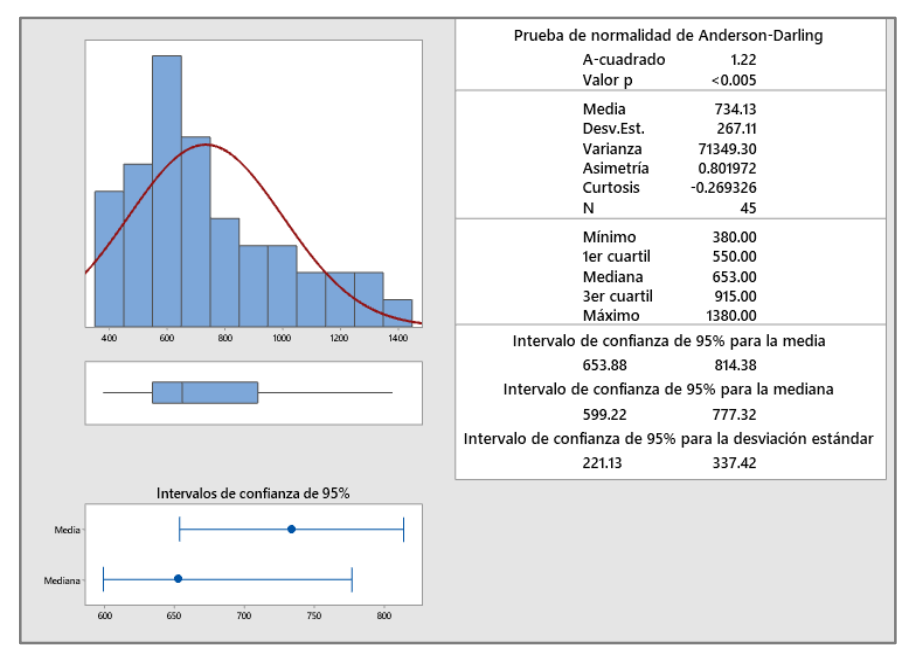

Fig. 9. KPI1 Post-Test Air Quality Pollution Volume Level.

The "average" difference of individual observations of air quality pollution volume level from the mean is $267.11 \mathrm{ppm}$.

About $95 \%$ of the air quality pollution volume level are within 2 standard deviations of the mean, i.e., between 653.88 and $814.38 \mathrm{ppm}$. The 1st Quartile $(\mathrm{Q} 1)=550 \mathrm{ppm}$, tells us that $25 \%$ of the volume level of air quality pollution is less than or equal to this value. The 3rd Quartile $(\mathrm{Q} 3)=915 \mathrm{ppm}$, tells us that $75 \%$ of the volume level of air quality pollution is less than or equal to this value.

Fig. 10 shows the conclusion of the normality test of the KPI-I data obtained from the post-test. The data obtained shows that the p-value is less than 0.05 , which confirms that the information analyzed has a non-normal behavior.

\section{B. Results of the Second Indicator (KPI - II)}

The summary report of the second Post System Implementation indicator, detailed in Fig. 11, is shown.

The "average" difference of the individual observations of the $\mathrm{CO} 2$ pollution volume level relative to the mean is 257.94 ppm.

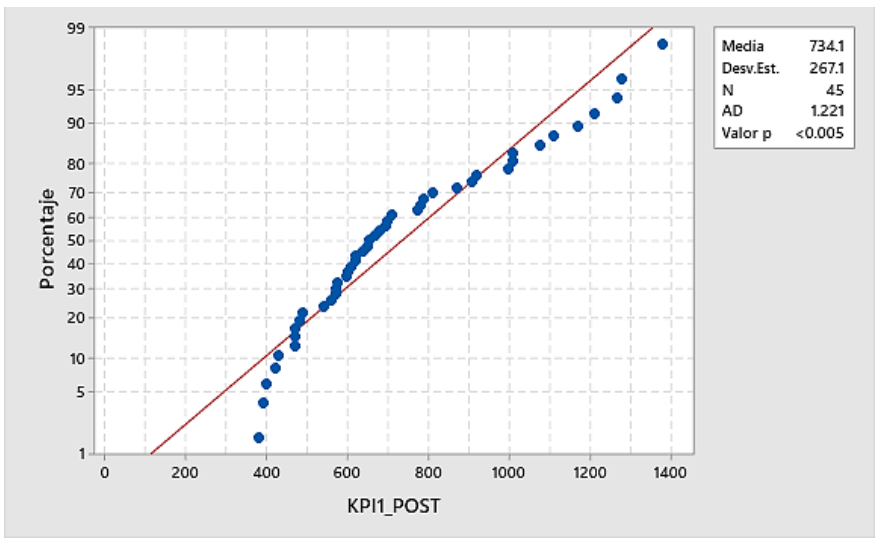

Fig. 10. Normality Test KPI1 Post-Test. 


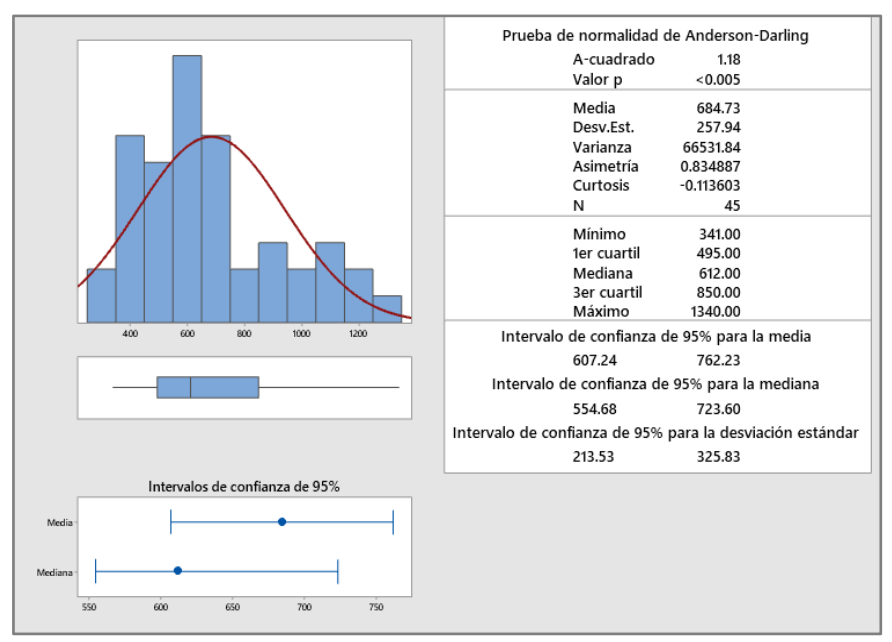

Fig. 11. KPI2 Post-Test CO2 Contamination Volume Level.

About $95 \%$ of the $\mathrm{CO} 2$ pollution volume level are within 2 standard deviations of the mean, i.e., between 607.24 and $762.23 \mathrm{ppm}$. The 1st Quartile $(\mathrm{Q} 1)=495 \mathrm{ppm}$, tells us that $25 \%$ of the volume level of $\mathrm{CO} 2$ pollution is less than or equal to this value. The 3rd Quartile (Q3) $=850 \mathrm{ppm}$, tells us that $75 \%$ of the volume level of $\mathrm{CO} 2$ pollution is less than or equal to this value.

Fig. 12 shows the conclusion of the normality test of the KPI-II data obtained from the post-test. The data obtained shows that the p-value is less than 0.05 , which confirms that the information analyzed has a non-normal behavior.

\section{Results of the Third Indicator (KPI - III)}

The summary report of the third Post System Implementation indicator, detailed in Fig. 13, is shown.

The "average" difference of the individual observations of the time to obtain air data relative to the mean is 1.25 seconds.

About $95 \%$ of the time to obtain information from the air are within 2 standard deviations of the mean, i.e., between 6.17 and 6.93 seconds. The 1st Quartile $(\mathrm{Q} 1)=5.5$ seconds, tells us that $25 \%$ of the time to obtain information from the air is less than or equal to this value. The 3rd Quartile $(\mathrm{Q} 3)=8$ seconds, tells us that $75 \%$ of the time to obtain information from the air is less than or equal to this value.

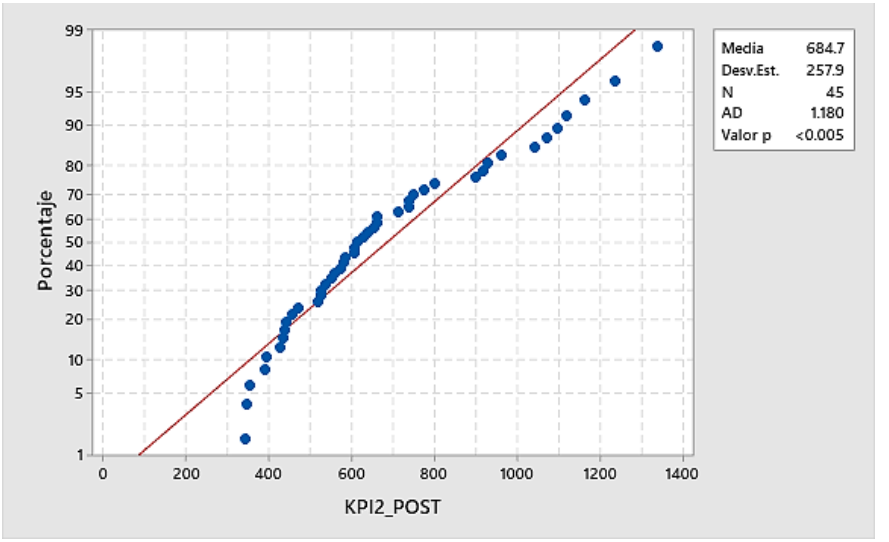

Fig. 12. KP2 Post-test Normality Test.

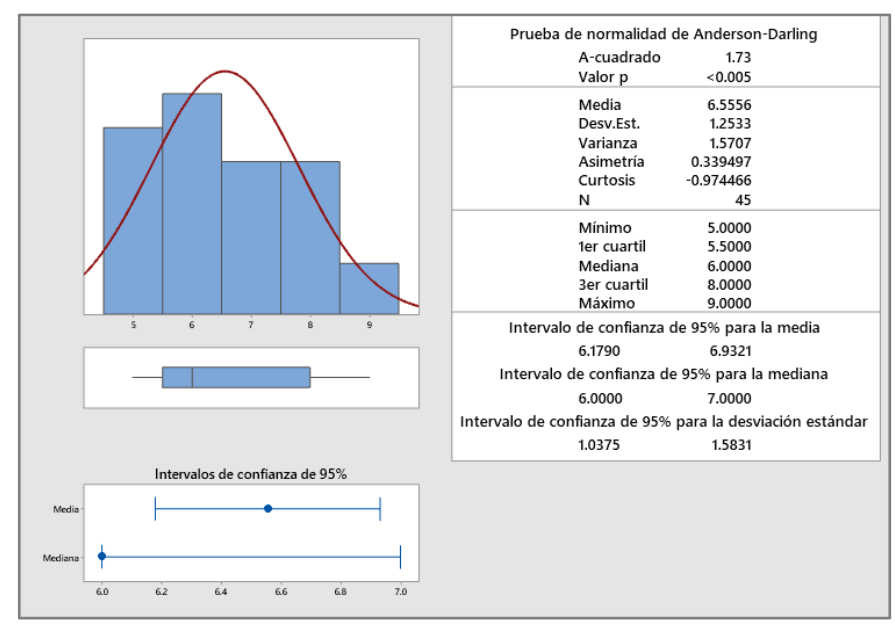

Fig. 13. KPI3 Post-Test Time to Obtain Information from the Air.

Fig. 14 shows the conclusion of the normality test of the KPI-III data obtained from the post-test. The data obtained shows that the p-value is less than 0.05 , which confirms that the information analyzed has a non-normal behavior.

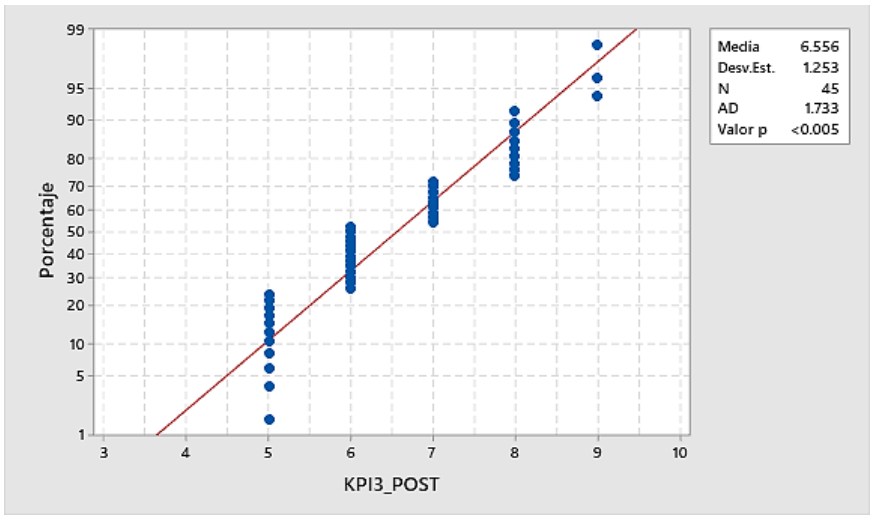

Fig. 14. KP3 Post-Test Normality Test.

\section{DISCUSSION}

The positive impact of the development of the control system solution on the 3 indicators (Fig. 9, Fig. 11, Fig. 13), carried out on the sample, was verified.

According to Table IV and Fig. 8, it was identified that the use of the control system reduces the volume level of air quality pollution (Post-Test) compared to the sample to which it was not applied (Pre-Test). In addition, the use of the control system reduces the volume level of $\mathrm{CO} 2$ contamination (PostTest) compared to the sample to which it was not applied (PreTest). Finally, it was identified that the use of the control system reduces the time to obtain information from the air (Post-Test) compared to the sample to which it was not applied (Pre-Test).

In the present investigation, a confidence level of $95 \%$ was established, so a margin of error or significance level of $5 \%$ was considered. Considering that the value of $p=0.000<\alpha=$ 0.05 , the resulting data in Fig. 10, Fig. 12, Fig. 14 provide sufficient evidence to reject the null hypothesis, the test being significant. 


\section{CONCLUSION}

Finally, it was possible to conclude that the use of the control system evidenced a significant improvement in the air quality of the closed establishment, this is because the polluting gases of the air decreased from $1260 \mathrm{ppm}$ to $670 \mathrm{ppm}$ achieving to be within the standards recommended by WHO; this information was obtained thanks to the sensors installed, in addition to their correct operation in the activation of the ventilation systems of the place, thus fulfilling the proposed objective.

It was possible to verify that with the application developed, the air status collection time was considerably reduced; the time decreased from 350 seconds to 5 seconds since this is constantly shown in the application managed by the manager.

When obtaining the data after the implementation of the system it was possible to verify that the amount of $\mathrm{CO} 2$ present in the air decreased, having a $\mathrm{CO} 2$ presence of $1150 \mathrm{ppm}$ before the implementation of the system in the air, however, after the use of the system it decreased to $650 \mathrm{ppm}$, being among the positive indexes.

It was verified that the use of free hardware was able to work correctly, having previously performed the corresponding calibrations and tests of the systems involved in the project, such as sensors and the ESP8266 module.

The scientific contribution provided by this research article is fundamental for the development of future related works serving as a basis, in order to improve the quality of life of people and contribute to the awareness of the damage generated to the environment by the hand of man himself. It is proposed to make improvements in the topic developed through the implementation of new technologies such as artificial intelligence and analysis of data, also make improvements in the hardware and software model as in the case of the application, making it compatible with other operating systems, because betting on developing a hybrid application helps to optimize time, making it possible to generate an application for both Android and IOS.

\section{REFERENCES}

[1] A. Ramos-Romero, B. Garcia-Yataco, and L. Andrade-Arenas, "Mobile Application Design with IoT for Environmental Pollution Awareness," Int. J. Adv. Comput. Sci. Appl., vol. 12, no. 1, p. 2021, 2021, doi: 10.14569/IJACSA.2021.0120165.

[2] F. Perera, "Pollution from fossil-fuel combustion is the leading environmental threat to global pediatric health and equity: Solutions exist," Int. J. Environ. Res. Public Health, vol. 15, no. 1, 2018, doi: 10.3390/ijerph15010016.

[3] United States Environmental Protection Agency, "Introduction to Indoor Air Quality," US EPA, 2021. https://www.epa.gov/indoor-air-qualityiaq/introduction-indoor-air-quality.

[4] World Health Organization, "New WHO Global Air Quality Guidelines aim to save millions of lives from air pollution," WHO, 2021. https://www.who.int/news/item/22-09-2021-new-who-global-airquality-guidelines-aim-to-save-millions-of-lives-from-air-pollution

[5] Dirección General de Industria; Energía y Minas de la Comunidad de Madrid, "Guía de Calidad del Aire Interior," Fenercom, p. 186, 2016, Available: https://www.diba.cat/documents/467843/172263104/Guia _qualitat_aire.pdf/eeba42ef-8af3-40e4-b4b3-2f399ed91f31.
[6] L. Barrie and G. Braathen, "Wmo Greenhouse Gas Bulletin: The State of Greenhouse Gases in the Atmosphere Based on Global Observations through 2020," World Meteorol. Organ., 2020.

[7] K. Lee and M. Greenstone, "Air Quality Life Index | Annual Update," AQLI, pp. 16-17, 2021. Available: https://aqli.epic.uchicago.edu/ pollution-facts/.

[8] A. Ochoa Duarte, L. D. Cangrejo Aljure, and T. Delgado, "Alternativa Open Source en la implementación de un sistema IoT para la medición de la calidad del aire.," Rev. Cuba. Ciencias Informáticas, vol. 12, no. 1, pp. 189-204, 2018.

[9] R. R. Urquijo and M. J. Marinelli, "Sistema de monitoreo de una cámara de germinación hidropónica con IoT basado en Raspberry Pi," AGRANDA, Simp. Argentino Gd. Datos, vol. 4, pp. 64-73, 2017.

[10] M. G. Retuerto, D. Y. Espinoza, and L. Andrade-Arenas, "System Dynamics Modeling for Solid Waste Management in Lima Peru," Int. J. Adv. Comput. Sci. Appl., vol. 12, no. 7, p. 2021, 2021, doi: 10.14569/IJACSA.2021.0120762.

[11] World Health Organization, “Ambient (outdoor) air pollution,” WHO, 2021. https://www.who.int/news-room/fact-sheets/detail/ambient(outdoor)-air-quality-and-health.

[12] R. Perez (WHO-E) and E. Appoh (Ghana-E), "WHO global air quality guidelines," Germany, 2021. Available: https://cdn.who.int/media/ docs/default-source/air-quality-and-health/who-global-aqgs.-afropresentation-2-nov-2021_final.pdf?sfvrsn=7d2f3da7_5.

[13] World Health Organization, "Household air pollution and health," WHO, 2021. https://www.who.int/news-room/fact-sheets/detail/house hold-air-pollution-and-health.

[14] R. UlAmin, M. Akram, N. Ullah, M. Ashraf, and A. Sattar, "IoT Enabled Air Quality Monitoring for Health-Aware Commuting Recommendation in Smart Cities," Int. J. Adv. Comput. Sci. Appl., vol. 11, no. 6, 2020, doi: 10.14569/JJACSA.2020.0110637.

[15] J. L. Diaz-Resendiz, A. E. Guerrero-Sanchez, M. Toledano-Ayala, and E. A. Rivas-Araiza, "IoT Based ambient monitoring system for intelligent buildings," IEEE ICA-ACCA 2018 - IEEE Int. Conf. Autom. Congr. Chil. Assoc. Autom. Control Towar. an Ind. 4.0 - Proc., pp. 1-6, 2019, doi: 10.1109/ICA-ACCA.2018.8609862.

[16] A. Delgado et al., "Comparative Analysis of the Impact on Air Quality Due to the Operation of La Oroya Metallurgical Complex using the Grey Clustering Method," Int. J. Adv. Comput. Sci. Appl., vol. 12, no. 2, pp. 450-454, 2021, doi: 10.14569/IJACSA.2021.0120257.

[17] V. Hable-Khandekar and P. Srinath, "Machine Learning Techniques for Air Quality Forecasting and Study on Real-Time Air Quality Monitoring," 2017 Int. Conf. Comput. Commun. Control Autom. ICCUBEA 2017, pp. 1-6, 2018, doi: 10.1109/ICCUBEA.2017.8463746.

[18] Y. C. Wang and G. W. Chen, "Efficient Data Gathering and Estimation for Metropolitan Air Quality Monitoring by Using Vehicular Sensor Networks," IEEE Trans. Veh. Technol., vol. 66, no. 8, pp. 7234-7248, 2017, doi: 10.1109/TVT.2017.2655084.

[19] S. Mansour, N. Nasser, L. Karim, and A. Ali, "Wireless sensor networkbased air quality monitoring system," 2014 Int. Conf. Comput. Netw. Commun. ICNC 2014, pp. 545-550, 2014, doi: 10.1109/ICCNC. 2014.6785394.

[20] J. Dutta, F. Gazi, S. Roy, and C. Chowdhury, "AirSense: Opportunistic crowd-sensing based air quality monitoring system for smart city," Proc. IEEE Sensors, pp. 5-7, 2017, doi: 10.1109/ICSENS.2016.7808730.

[21] A. Tapashetti, D. Vegiraju, and T. Ogunfunmi, "IoT-Enabled Air Quality Monitoring Device," IEEE 2016 Glob. Humanit. Technol. Conf., pp. 0-3, 2016.

[22] A. A. Alkandari and S. Moein, "Implementation of Monitoring System for Air Quality using Raspberry PI: Experimental Study," Indones. J. Electr. Eng. Comput. Sci., vol. 10, no. 1, p. 43, Apr. 2018, doi: 10.11591/ijeecs.v10.i1.pp43-49.

[23] H. F. Hawari, A. A. Zainal, and M. R. Ahmad, "Development of real time internet of things (IoT) based air quality monitoring system," Indones. J. Electr. Eng. Comput. Sci., vol. 13, no. 3, p. 1039, Mar. 2019, doi: 10.11591/ijeecs.v13.i3.pp1039-1047. 
[24] S. Pandey, S. H. Saeed, and N. R. Kidwai, "Simulation and optimization of genetic algorithm-artificial neural network based air quality estimator," Indones. J. Electr. Eng. Comput. Sci., vol. 19, no. 2, p. 775, Aug. 2020, doi: 10.11591/ijeecs.v19.i2.pp775-783.
[25] J. Patricia, Z. Gamboa, C. Alexandra, and L. Arreaga, "Evolución de las Metodologías y Modelos utilizados en el Desarrollo de Software. Evolution of the Methodologies and Models used in Software Development," INNOVA Res. J., vol. 3, no. 10, pp. 20-33, 2018. 